\title{
XIII. On a simple apparatus for washing precipitates
}

\section{Eustace C. Summers}

To cite this article: Eustace C. Summers (1849) XIII. On a simple apparatus for washing precipitates , Philosophical Magazine, 35:234, 96-98, DOI: 10.1080/14786444908646316

To link to this article: http://dx.doi.org/10.1080/14786444908646316

曲 Published online: 30 Apr 2009.

Submit your article to this journal ¿

Q View related articles $₫$ 
I have calculated the horizontal attraction of a semicylinder of water 100 feet thick, and of about two, four, and eight miles radius upon a point at the extremity of the axis of such a semicylinder; because these conditions can easily be reduced to calculation, and because they represent very approximately the circumstances of an attracted point placed at high watermark on a vertical sea-wall facing a basin or estuary. The radius of the attracting mass of water being represented (more accurately) by $10,000,20,000$, and 40,000 feet, I find the influence of a tide-wave 100 feet thick upon a plumb-line to produce a deviation of only $0^{\prime \prime} \cdot 44$ (forty-four hundredths of a second), $0^{\prime \prime} \cdot 50$, and $0^{\prime \prime} \cdot 53$; the effect increasing extremely slowly with the radius, as might be expected. If the tide rose only fifty feet, the first effect would be reduced to $0^{\prime \prime} \cdot 24.6$.

Even the greatest of these calculated deviations affords no ground for hoping that the method of Robison could be applied with any success to determine the earth's density.

It is rather singular that this ingenious suggestion is not once alluded to, so far as I am aware, by any writer on the figure and density of the earth; yet surely it was as worthy of notice as Dr. Hutton's proposal to measure the attraction of an Egyptian pyranid. (Phil. Trans. 1821.)

\section{On a Simple Apparatus for Washing Precipitates.} By Eustace C. Summers*.

MY attention has been lately drawn to an account by $\mathrm{M}$. II Bloch, given in the May Number of the Annales de Chimie et de Physique, vol. xxvi. p. 126, 3rd series, of a new method of washing precipitates by means of a self-regulating siphon. The instrument proposed by M. Bloch is, however, open to several serious objections. In the first place, as soon as the requisite quantity of water has been supplied to the filter, the water rises in the exterior air-tube to the level of the liquid in the vessel from which the supply is obtained. Now if the precipitate be very light, part of it also is liable to gain access to the tube and adhere to its sides. Again, when the level of the water in the filter falls, the column of water in the air-tube does not always fall so as to leave free access to the air. On the contrary, the whole or part of it is frequently carried upwards by the pressure of the air, and falls, not into the filter, but into the reservoir; and should any of the precipitate be carried with it, which is far from improbable, of course an analysis might be at once invalidated. I say

- Communicated by the Author. 
nothing of the difficulty, which, however, is by no means slight, of bending the two concentric tubes; because all the advantages, together with greater convenience for washing, \&c., may be obtained by having the tubes entirely distinct.

The apparatus of M. Gay-Lussac, as described in Mohr and Redwood's Pharmacy, is far superior to that now proposed by M. Bloch, inasmuch as the air-tube does not communicate with the fluid in the filter. The following contrivance has, however, occurred to me as furnishing the most simple and effectual way of attaining the object in view, and has the advantage of being applicable upon any scale of magnitude.

It consists of a reservoir, fig. $a$, having the mouth placed at its base. This, when the vessel is filled with water, is closed by a cork, pierced by a straight tube $b$, passing through it obliquely downwards. It is now obvious that the water will rise in the tube $b$ so long as air can gain access to the interior of the reservoir; which, however, is prevented when the water in the tube is sufficiently high to cover the whole of its lower ex-

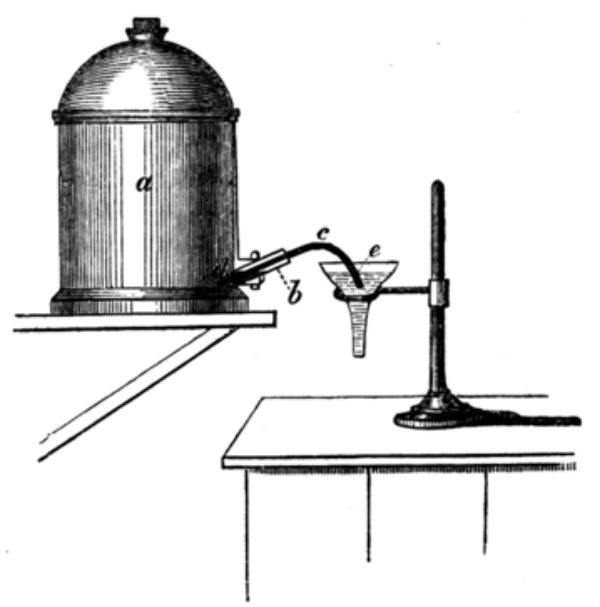
tremity. A siphon is then introduced through this tube so as to project into the reservoir slightly beyond the lower extremity of the tube, care being taken to leave sufficient space to allow of the passage of air between the siphon and the surrounding tube. The funnel is placed beneath the long leg of the siphon, so that the edge of the filter is a little above the level of the water in the straight tube. In this condition the apparatus works. As long as the level of the water in the filter is lower than the level of that in the tube $b$, the column of water $c e$ will be heavier than the column $c d$, and consequently the siphon will keep up a supply of water, bubbles of air obtaining access to the interior of the reservoir, as the level of the water in the tube $b$ is reduced by the action of the siphon. But no sooner does the water in the filter attain the same level with that in the tube, than the column of water $c d$ is equal in pressure to the column $c e$, and consequently the action Phil. Mag. S. 3. Vol. 35. No. 234. Aug. 184.9. 
of the siphon is stopped, the water in the tube $b$ remaining at just sufficient height to exclude the air from the interior of the reservoir.

This simple apparatus may be affixed to any convenient vessel having an aperture at the bottom; all other openings being of course closed, so as to prevent the ingress of air except by the tube $b$. A common salt glaze earthenware washing-bottle, or a Griffin's gas-holder, will be found to answer the purpose perfectly.

Glasgow College Laboratory, July 6, 1849 .

XIV. On the Sources of the Nile; being an attempt to assign the limits of the Basin of that River. By CHARLES T. BeкE, Esq., Ph.D., F.S.A. \&i.*

I $\mathrm{N}$ treating of the sources of the Nile, it is not intended to regard any particular source or spring as being more especially and exclusively the true head of that river. It will not even be discussed whether this or that large branch of the river should be considered to be the principal one. Such questions at the outset are not likely to lead to any satisfactory result. Our object must be in the first place to determine the entire limits of the basin of the river; we have next to ascertain what principal arms unite to form the main stream; we must then trace to their heads the several smaller streams which form those branches; and when we have succeeded in all these points, we shall then-but not before-be competent to decide which of these numerous ramifications has the fairest claim to be regarded as the true source of the Nile.

It may however be objected, and not without a show of reason, that though this is the theoretical method of investigating the subject, yet the question is susceptible of a more practical solution;-that, as in the case of most other rivers, there is some particular stream which by common consent is looked on as the source of the Nile, and this without regard to its being actually the head of the longest or the largest branch. Were this really the case, we should in one sense be bound to acquiesce in the recognition of such a source, even though it might not possess all the attributes of the true head of the river. But the fact is not so. The Abái, the river of Abessinia, whose source was visited and described by the Portuguese Jesuits in the beginning of the seventeenth

* Communicated by the Syro-Egyptian Society of London, having been read before that Society on the 9th of January 1849. 